\title{
Utilization of Partograph in the Management of Women in Labor among Nurses Working in Embu County, Kenya
}

\author{
Githae CN1, Mbisi $\mathrm{A}^{1}$ and Boraya J02* \\ 1Department of Community Health, Chuka University, Kenya \\ ${ }^{2}$ Department of Reproductive Health, Kenyatta University, Kenya
}

*Corresponding author: Joshua Omwenga Boraya, Department of reproductive health, Kenyatta University, 10337-00100, Nairobi, Kenya, Tel: 0721626033; Email: borayajoshua@gmail.com

\section{Research Article}

Volume 3 Issue 2

Received Date: February 21, 2019

Published Date: March 18, 2019

DOI: $10.23880 /$ nhij-16000181

\section{Abstract}

A partograph is a graphical representation of the fetal status, maternal status and progress of labor. Its proper interpretation assists in early identification of complications which may lead to morbidity and mortality. The study will determine the utilization of the partograph in management of women in labor in Embu County. The objectives of the study were to determine the level of utilization of the partograph, and nurses related factors influencing the utilization of the partograph. A cross-sectional study design was conducted in selected hospitals within Embu County. The study population comprised of 124 nurses working in maternity wards. Purposive sampling technique was used to choose health facilities under study while simple random sampling of participants was done. Structured questionnaires were used to collect quantitative data while focused group discussions was conducted and key informants interviewed for qualitative data. Data collected and analyzed using SPSS Version 23 and presented by use of tables, figures, bar charts and narration. Binary logistic regression was used to assess the possible association and strength of association was measured using 95\% confidence interval, chi-square was used to check for statistically significant results at a $\mathrm{p}$ value of 0.05. The study revealed that, nurses related factors influencing utilization of the partograph included negative attitude and lack of training on partograph use. Majority of nurses working in labor ward felt that partograph use is time consuming and needed supervision on partograph use. In addition, majority of the nurses were not trained on partograph use from the time they graduated from college. The study recommends policy makers and nursing administrators to ensure that all qualified nurses use the partograph in the care of women in labour.

Keywords: Partograph use; Utilization of the Partograph; Partogram use in Kenya

\section{Introduction}

The partogram which is also called a partograph is a graphical record used to monitor progress of women during labour. The partogram provides a pictorial overview of labour, alerts midwives and obstetricians to any deviations in maternal or fetal well-being and the progress of labour. It also assists in early decision making 


\section{Nursing \& Healthcare International Journal}

on transfer, augmentation or immediate delivery. The concept of a partogram was introduced by Friedman in 1954 by graphically plotting the dilation of the cervix against time during labour. Later after Friedman, Philpott and Castle in 1972 developed the partograph into a tool for monitoring labour by introduced the action and alert lines to the graphical record [1].

The World Health Organization (WHO) advocates the utilization of a partograph as the effective tool for monitoring labor and reducing labor complications in developing countries which is an important intervention in reducing both maternal and perinatal mortality and morbidity towards achieving the Millennium Development Goals 4 and 5 [2].
The different variables of a partogram includes: fetal condition which can be assessed through fetal heart rate, status of the membranes, quality of liquor and the degree of molding on the fetal head. The progress of labor records the rate of dilation of the cervix, strength and pattern of uterine contractions and the descent of the presenting part while maternal records includes maternal pulse rate, temperature, blood pressure and urine of the mother [3].

In Malawi, it was reported that most midwives partially documented the partograph charts. Poor documentation was attributed by shortage of staffs and knowledge gap on documentation. Other claimed that the chart was complex to fill Figure 1 [4].

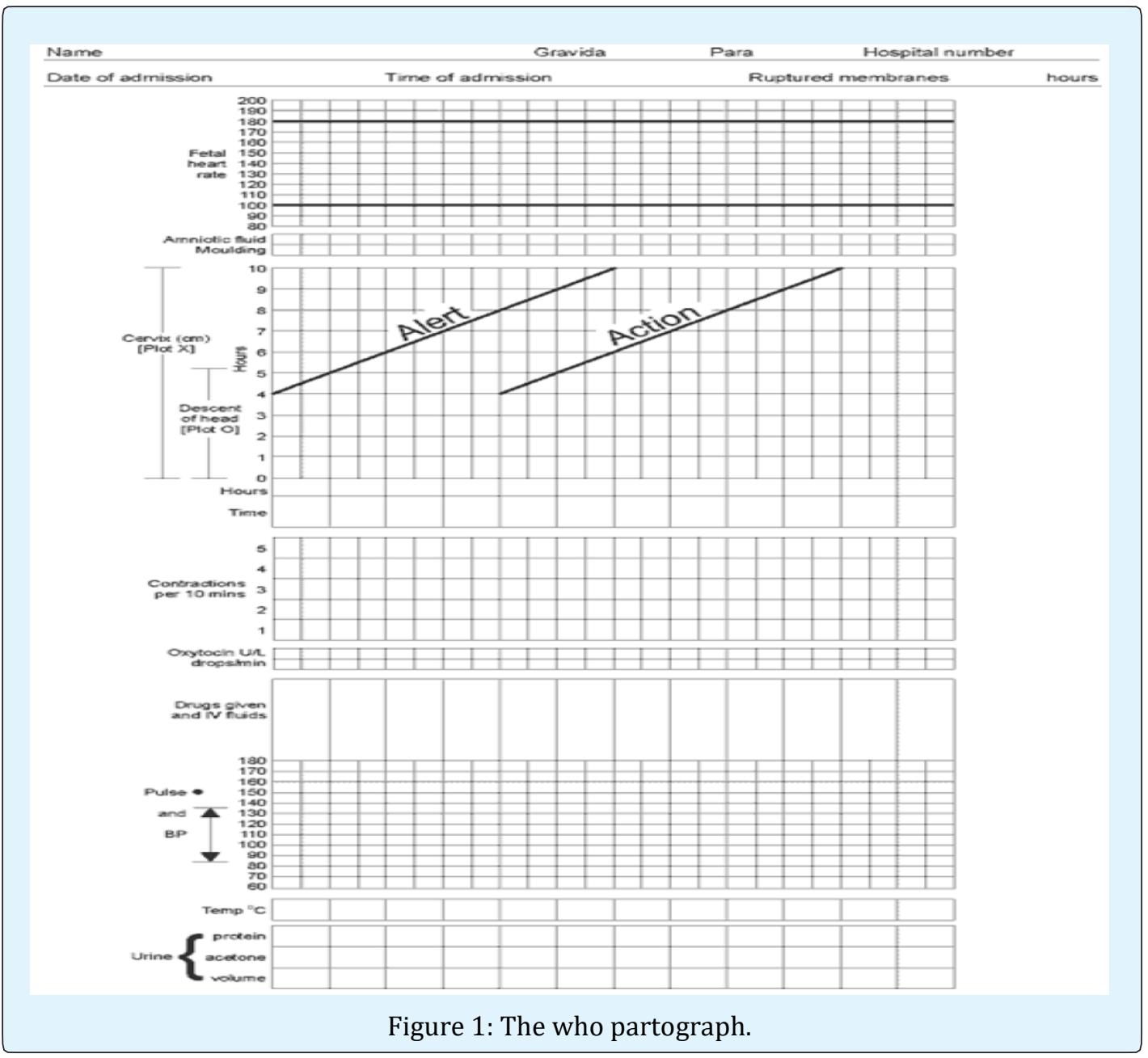

Kenya is still one of those developing countries with high maternal mortality ratio and neonatal mortality rate, estimated at 510/100,000 and 22/1000 live births [5,6]. Prolonged and obstructed labor accounts for $8-10 \%$ of maternal deaths while mechanical obstruction in second stage accounts for complications in about $1-2 \%$ of labor. Utilization of the partograph engender gross reduction in the number of deaths by ensuring that complications are 


\section{Nursing \& Healthcare International Journal}

detected early for prompt interventions thereby enhancing maternal and neonatal well-being [5].

However, a study in Kenyatta National Hospital on partograph use revealed that partographs were incomplete, incorrectly filled or not used at all [7]. Health records from selected hospitals in Embu County in regards to partograph utilization revealed that $100 \%$ of the records had a partograph attached with only $40 \%$ of them used correctly up to delivery. If nurses working in maternity wards used a partograph correctly in managing women in labor, there should be no complications which may lead to neonatal and maternal mortality. However, partograph use and documentation is a major problem in the majority of the health facilities which offer maternity services in Embu County.

\section{Research Questions}

- What is the level of utilization of the partograph in management of women in labor among nurses in Embu County?

- What are the nurses' related factors influencing utilization of the partograph in management of women in labor among nurses in Embu County?

\section{Specific Objectives}

- To assess the level of utilization of the partograph in management of women in labor among nurses in Embu County.

- To establish nurses related factors influencing utilization of the partograph in management of women in labor among nurses in Embu County.

\section{Methodology}

A cross-sectional study was used to describe the utilization of the partograph by nurses in selected hospitals within Embu County. This design was used because it gives a representation of the entire population under study. It also provides relevant facts and opinions of individuals.

\section{Study Area}

Embu County is situated in Eastern region of Kenya, was previously the head quarter of Eastern province. The County has an approximate total population of 543, 221 persons and occupies about $2,818 \mathrm{~km}^{2}$. It is bordered by Kirinyaga County to the west, Tharaka Nithi County to the north, Kitui County to the east, and Machakos County to the south. Embu county is between latitude $0^{\circ} 32^{\prime} \mathrm{S}$ and longitude $37^{\circ} 27^{\prime} \mathrm{E}$.

\section{Study Variables}

Dependent variable: The dependent variable was utilization of the partograph.

Independent variables: Independent variables were nurses related factors influencing utilization of the partograph which included; knowledge, attitude, training, and experience.

\section{Study Population}

The study targeted nurses working in maternity departments within the selected hospitals in Embu County, Kenya. Nurses participated in filling structured questionnaire and others in focus group discussion. The key informants included nurse in charges with midwifery background among the selected hospitals.

\section{Inclusion criteria}

- Qualified nurses who had worked in maternity department for six months in selected hospitals.

- Nurses who gave informed consent to participate in the study.

\section{Exclusion criteria}

- Nurses who were sick at the time of data collection.

- Nurses who were not of sound mind during the time of the study.

\section{Sample Size Determination}

The sample was determined using the formula as designed by Fisher, et al. (1998),

$$
\mathrm{n}=\frac{\mathrm{z}^{2} \mathrm{p}(1-\mathrm{p})}{\mathrm{d}^{2}}
$$

$\mathbf{Z}$ is the $\mathrm{Z}$ value for the corresponding confidence level (i.e., 1.96 for $95 \%$ confidence);

d is the margin of error (i.e., $0.05= \pm 5 \%$ ) and

$\mathbf{p}$ is the estimated value for the proportion of a sample that have the condition of interest.

$\mathbf{P}=50 \%$ (the most conservative estimate) $=0.5$. The prevalence of partograph utilization is unknown in the study area.

$$
\mathrm{n}=\frac{1.96^{2} \mathrm{p}(1-\mathrm{p})}{0.05^{2}} \mathrm{n}=\frac{1.96^{2} 0.5(1-0.5)}{0.05^{2}} \mathrm{n}=384
$$

Finite population correction for proportion

$$
\mathrm{nf}=\frac{\frac{\mathrm{n}}{1+\mathrm{n}}}{\mathrm{N}}
$$




\section{Nursing \& Healthcare International Journal}

Where $\mathrm{nf}=$ desired sample size

$\mathbf{n}=$ Calculated sample size.

$\mathbf{N}=$ Estimate of population in study area was 160 nurses working in maternity department in selected hospitals as at January 2019.

$$
\mathrm{nf}=\frac{\frac{384}{1+384}}{160}=113
$$

Hence the Sample size was 113 add $10 \%$ of non- response rate which gave a sample size of 124 .

Total sample size $=124$.

\section{Research Instruments}

Data was collected using structured interviews in a questionnaire form to afford quantitative analysis. The questionnaire will feature both closed and open-ended questions. A combination of both qualitative and quantitative questions was used to collect data. Quantitative data collection was used to obtain facts and opinion of individuals, give most accurate and realistic picture of knowledge on importance of utilization of the partograph in management of labor and challenges encountered by nurses in regards to partograph utilization. Focus group discussions were conducted to explore, attitudes and opinions towards partograph use. A focus group discussion guide was used as outlined in appendix. Key Informant Interviews was conducted among maternity in charges (with midwifery background) because they had knowledge and understanding of the study and they gave insight on the nature of the problem and recommendations on the same. A Key Informants guide was used.

The questionnaire was pre-tested in Consolata Hospital Kyeni, in Embu County which has similar characteristics to the hospitals under study. It was administered to 12 respondents (10 percent of the sample size). This allowed for modifications on the questionnaires by correcting mistakes and inclusion of questions that had been missed out or elimination of questions that were not be applicable.

To ensure validity, the questionnaire was tested, issues which were not clear were clarified, all questions were thoroughly scrutinized by technical persons and those which were not necessary were deleted. Those questions that needed to be rephrased were edited accordingly before the study was commenced. Content validity was ensured through proof reading and peer review of the tool before it was subjected to the respondents.
A pretest was carried out to determine reliability of the questionnaires. Reliability analysis was subsequently done using Cronbach's Alpha which measured the internal consistency by establishing if certain item within a scale measures the same construct. Gliem, et al. (2003) established the Alpha value threshold at 0.7, thus forming the study's benchmark. In this study, Cronbach Alpha was established for every objective which formed a scale. Nurses related factors influencing partograph utilization had the highest reliability $(\alpha=0.875)$, this illustrates that all the variables were reliable as their reliability values exceeded the prescribed threshold of 0.7 .

\section{Data Analysis and Management}

Data collected was coded, entered into the computer, cleaned and analyzed using the Statistical Package for the Social Sciences (SPSS) software, version 23. Data was then summarized using descriptive statistics such as frequencies and presented by use of tables, figures, and narration. Logistic regression was used to test for association between variables and level of significance. Results from FGDs and KIIs were categorized into common themes from which inferences were made and conclusions drawn during thematic analysis. Qualitative data was used to supplement, explain and interpret quantitative data.

\section{Utilization Measurement}

A retrospective spot check was done on the files of mothers who had already delivered within one week before the study under the assistance of the nurses involved in the study. The level of utilization was then measured using a utilization level scale where a score of 1 was awarded for those which were dully completed while a score of 0 was given to those files which were not dully completed. The number of files from each facility was proportionate with number of participants. This promoted representativeness and validity of the information on partograph utilization among nurses from the selected health facilities.

\section{Knowledge Measurement}

Knowledge scale was used to measure knowledge whereby each item on the questionnaire was scored 1 for correct response and 0 for incorrect response then scores were added and classified as; High knowledge (75-100\%), Moderate knowledge (50-75\%) and Low knowledge $(<50 \%)$.

\section{Nurse's Attitude Measurement Tool}

A Likert scale was used. Four statements were used to assess the attitude of nurses. Each of the statements will 
rated on 5 scale; strongly agree, agree, neutral (not sure), disagree and strongly disagree. Then after data collection and entry, a general level of attitude was computed to assess how the nurse's attitude affects use of the partograph.

\section{Logistical and Ethical Considerations}

Approval to conduct the study was sought from Medical officers (Medical facility Heads) in each selected Hospitals. The nursing officers in charges of the selected hospitals were informed. The questionnaires were administered to the respondents upon obtaining an informed consent. To ensure privacy, names and other means of identity will not be used during the data collection. The researcher will ensure that all information obtained was kept in strict confidence and only be used for the sole purpose of the study.

\section{Results}

The study targeted a sample size of 124 nurses working in maternity departments from which 110 filled in and returned the questionnaires making a response rate of $88.7 \%$. This response rate was satisfactory to make conclusions for the study as it acted as a representative. According to Mugenda, et al. (2003), a response rate of 50\% is adequate for analysis and reporting; a rate of $60 \%$ is good and a response rate of $70 \%$ and over is excellent. Based on the assertion, the response rate was excellent Table 1.

\section{Reliability Analysis}

\begin{tabular}{|c|c|c|}
\hline Scale & $\begin{array}{c}\text { Cronbach's } \\
\text { Alpha }\end{array}$ & $\begin{array}{c}\text { Number of } \\
\text { Items }\end{array}$ \\
\hline $\begin{array}{c}\text { Nurses Related Factors } \\
\text { Influencing Partograph } \\
\text { Utilization }\end{array}$ & 0.875 & 3 \\
\hline
\end{tabular}

Table1: Reliability analysis table.

Demographic characteristics of the participants: The study involved nurses who had worked in labor ward for at least six months. The study established that more than half of the respondents 78 (70.9\%) were female. The mean age of the respondents was calculated to be 26 years and nearly half of them $58(52.7 \%)$ were within the age group of 25-30 years. A considerable number of respondents, 91 (82.5\%) were diploma holders in Kenya Registered community health nursing, $11(10 \%)$ had a diploma in midwifery and $8(7.5 \%)$ had a degree in nursing, the remaining respondents had a certificate in nursing. Majority of health care providers $93(84.5 \%)$ had worked in labor ward for less than six years Table 2.

\begin{tabular}{|c|c|c|c|}
\hline Variables & Categories & $\begin{array}{c}\text { Frequency } \\
(\mathrm{N}=110)\end{array}$ & Percentage \\
\hline \multirow{2}{*}{ Gender } & Male & 32 & 29.1 \\
\hline & Female & 78 & 70.9 \\
\hline \multirow{3}{*}{ Age in Years } & $\leq 24$ years & 29 & 26.4 \\
\hline & 24-30 Years & 58 & 52.7 \\
\hline & $\geq 30$ Years & 23 & 20.9 \\
\hline \multirow{3}{*}{ Health institution } & Kianjokoma hospital & 58 & 52.7 \\
\hline & Kiritiri hospital & 30 & 27.3 \\
\hline & Kibugu hospital & 22 & 20 \\
\hline \multirow{3}{*}{ Qualification Level } & Certificate & 9 & 8.2 \\
\hline & Diploma & 93 & 84.5 \\
\hline & Degree & 8 & 7.3 \\
\hline \multirow{3}{*}{ Years of experience in labor ward } & 6 Months $\leq 3$ years & 27 & 24.5 \\
\hline & 3-6 years & 66 & 60 \\
\hline & $\geq 6$ years & 17 & 15.5 \\
\hline \multirow{3}{*}{ The profession of the respondent } & KRCHN & 91 & 82.5 \\
\hline & Midwifery & 11 & 10 \\
\hline & Degree in nursing & 8 & 7.5 \\
\hline
\end{tabular}

Table 2: Social demographic characteristics of the participants. 


\section{Level of Utilization of Partograph Charts among Nurses in Embu County}

The results of study revealed that majority of the nurses, $61(55.5 \%)$ did not duly complete the partograph charts available in labor ward. This was attributed to a number of factors ranging from nurses related factors and health institution related factors from where they were working Table 3.

\begin{tabular}{|c|c|c|c|}
\hline Variable & Category & Frequency & Percentage \\
\hline General utilization of the partographs in labor ward from selected & Duly completed & 49 & 44.5 \\
\cline { 2 - 4 } hospitals & Not completed & 61 & 55.5 \\
\hline
\end{tabular}

Table 3: Utilization of the partograph among nurses in Embu County.

\section{Nurses Related Factors Influencing Utilization of Partograph}

Nurses knowledge on use of partograph: Under this subsection a number variables were assessed on nurse's knowledge on partograph use. This was assessed based on specific questions. Each correct response was awarded one point while incorrect responses attracted no mark.

Majority of the respondents $88(80 \%)$ were able to define a partograph, out of these, 49 (44.5\%) of them had duly completed the partograph charts while 39 of them never made use of the available charts. A considerable portion of respondents, $96(87.3 \%)$ were able to tell when to start plotting a partograph $(\mathrm{p}=0.346)$, and more than half of the respondents 74 (67.2\%) knew the meaning of alert line, these were also not significantly associated with use of partographs $(p=0.696)$ while $80(72.7 \%)$ of the respondents knew the function of an action line and were able to explain its meaning on a partograph Table 4 .

On how often the partograph is used, the nurse in charge reported that partographs were used regularly, Partographs are often used to monitor the progress of women in labor on a regular basis (key informer from Kianjokoma hospital). This was reported by the informant, "it is a requirement of the hospital for every mother in active labor be monitored using a partograph" (key informant from Kibugu hospital).

\begin{tabular}{|c|c|c|c|c|c|}
\hline \multirow[t]{2}{*}{ Variable } & \multirow[t]{2}{*}{ Category } & \multicolumn{2}{|c|}{$\begin{array}{l}\text { Utilization of partograph } \\
(\mathrm{N}=110)\end{array}$} & Pdf $\chi^{2}$ & $\begin{array}{l}\text { Likelihood } \\
\text { Ratio }\end{array}$ \\
\hline & & Used & Not used & \multirow{3}{*}{$\begin{array}{c}\mathrm{P}=0.924 \mathrm{df}=1 \\
\chi^{2}=0.767\end{array}$} & \multirow{3}{*}{$\mathrm{OR}=0.81$} \\
\hline \multirow{2}{*}{ Definition of partograph } & $\begin{array}{l}\text { Correct } \\
\text { response }\end{array}$ & $49(44.5 \%)$ & $39(35 \%)$ & & \\
\hline & $\begin{array}{c}\text { Wrong } \\
\text { response }\end{array}$ & $12(11 \%)$ & $10(9 \%)$ & & \\
\hline \multirow{2}{*}{$\begin{array}{c}\text { When to start plotting a } \\
\text { partograph }\end{array}$} & $\begin{array}{l}\text { Correct } \\
\text { response }\end{array}$ & $51(46.3 \%)$ & $45(41 \%)$ & \multirow{2}{*}{$\begin{array}{c}P=0.346 \mathrm{df}=1 \\
\chi^{2}=0.890\end{array}$} & \multirow{2}{*}{$\mathrm{OR}=0.836$} \\
\hline & $\begin{array}{c}\text { Wrong } \\
\text { response }\end{array}$ & $10(9 \%)$ & $4(4 \%)$ & & \\
\hline \multirow{2}{*}{ Meaning of alert line } & $\begin{array}{c}\text { Correct } \\
\text { response }\end{array}$ & $38(35.2 \%)$ & $36(33 \%)$ & \multirow{2}{*}{$\begin{array}{c}\mathrm{P}=0.696 \mathrm{df}=1 \\
\chi^{2}=0.152\end{array}$} & \multirow{4}{*}{$\mathrm{OR}=0.151$} \\
\hline & $\begin{array}{l}\text { Wrong } \\
\text { response }\end{array}$ & $23(21 \%)$ & $13(12 \%)$ & & \\
\hline \multirow{2}{*}{ Function of action line } & $\begin{array}{l}\text { Correct } \\
\text { response }\end{array}$ & $39(35.4 \%)$ & $41(37 \%)$ & \multirow{2}{*}{$\begin{array}{c}P=0.089 \mathrm{df}=1 \\
\chi^{2}=9.782\end{array}$} & \\
\hline & $\begin{array}{l}\text { Wrong } \\
\text { response }\end{array}$ & $22(20 \%)$ & $8(7 \%)$ & & \\
\hline
\end{tabular}

Table 4: Nurses knowledge on use of partograph.

Frequency of monitoring different parameters within the partograph: On monitoring fetal heart rate, majority of the respondents $83(75.5 \%)$ knew how frequent to monitor fetal heart rate during active phase of labor $(\mathrm{p}=0.112, \chi 2=2.53)$. Most respondents 103 (93.6\%) knew the frequency of monitoring cervical dilatation during labor Table 5.

In FGD conducted among the group of nurses revealed that cervical dilatation, descent and contractions featured 


\section{Nursing \& Healthcare International Journal}

as what was mostly filled on the partograph, I mostly plot the cervical dilatation, descent of the fetal head and the number of contractions on the partograph (FGD nurse from Kiritiri hospital).

\begin{tabular}{|c|c|c|c|c|}
\hline \multirow{2}{*}{ Variable } & \multirow{2}{*}{ Category } & \multicolumn{2}{|c|}{ Use of partograph } & \multirow{2}{*}{$P, \mathrm{df}, \chi^{2}$} \\
\hline & & Yes & No & \\
\hline \multirow{2}{*}{$\begin{array}{l}\text { Frequency of monitoring fetal heart } \\
\text { rate }\end{array}$} & Correct response & $43(39 \%)$ & $40(36.3 \%)$ & \multirow{2}{*}{$\mathrm{P}=0.177 \mathrm{df}=1 \chi^{2}=2.53$} \\
\hline & Wrong response & $18(16 \%)$ & $9(8 \%)$ & \\
\hline \multirow{2}{*}{$\begin{array}{c}\text { Frequency of monitoring cervical } \\
\text { dilatation }\end{array}$} & Correct response & $55(50 \%)$ & $43(39 \%)$ & \multirow{2}{*}{$\mathrm{P}=0.687 \mathrm{df}=1 \chi^{2}=0.441$} \\
\hline & Wrong response & $6(5 \%)$ & $6(5 \%)$ & \\
\hline
\end{tabular}

Table 5: Frequency of monitoring parameters on the partograph.

Knowledge of nurses on complications that are detected using a partograph: More than half of the respondents $93(84.5 \%)$ were knowledgeable on detection of maternal distress, with the same proportion able to interpret the colors of amniotic fluid. The ability to detect and act in case of a maternal distress was significantly associated with use of the partograph $\left(\mathrm{p}=0.015, \chi^{2}=5.889\right)$. Almost the same proportion of respondents 98 (85\%) were able to detect fetal distress during labor, this was also significantly associated with partograph use $\left(\mathrm{p}=0.040, \chi^{2}=4.238\right)$.

This was echoed during Key Informant Interview with the nursing officer in charge who reported that In case of maternal distress or fetal distress all my nurses quickly call the MO (medical officer) for the patient to be done CS (Caesareans section), they don't hesitate (KII nurses from Kianjokoma hospital).

It was evident from the responses that 93 (84.5\%) of the nurses knew the obstetric complications that a mother in labor can suffer from but when this was computed in a Chi-square it was found to be insignificant $(\mathrm{p}=0.159)$, and $94(85.5 \%)$ of them knew when to refer a mother in labor for caesarean section (CS). All the respondents knew when to complete documenting a partograph Table 6.

\begin{tabular}{|c|c|c|c|c|c|}
\hline \multirow{2}{*}{ Variable } & \multirow{2}{*}{ Category } & \multicolumn{2}{|c|}{ Use of partograph $(\mathrm{N}=110)$} & P df $\chi^{2}$ & Likelihood Ratio \\
\hline & & Used & Not used & \multirow{3}{*}{$\mathrm{P}=0.015 \mathrm{df}=1 \chi^{2}=8.006$} & \multirow{3}{*}{$\mathrm{OR}=7.119$} \\
\hline \multirow{2}{*}{$\begin{array}{l}\text { Ability to detect } \\
\text { maternal distress }\end{array}$} & Correct response & $47(42.7 \%)$ & $46(41.8 \%)$ & & \\
\hline & Wrong response & $14(13 \%)$ & $3(2)$ & & \\
\hline \multirow{2}{*}{$\begin{array}{l}\text { Ability to detect } \\
\text { fetal distress }\end{array}$} & Correct response & $51(46.3 \%)$ & $47(43 \%)$ & \multirow{2}{*}{$\mathrm{P}=0.040 \mathrm{df}=1 \chi^{2}=6.866$} & \multirow{2}{*}{$\mathrm{OR}=11.011$} \\
\hline & Wrong response & $10(9 \%)$ & $2(2 \%)$ & & \\
\hline
\end{tabular}

Table 6: Knowledge of nurses on complications detected using a partograph.

General knowledge on partograph: Generally, 77 (70\%) of the respondents knew when and what to use a partograph for, and reported to have used a partograph before the time of study. Only $80(72.7 \%)$ of the respondents exactly knew that a partograph is started when the cervical dilatation is at four centimeters. Majority of the nurses $69(62.7 \%)$ knew the meaning of the alert line and were able explain its meaning on a partograph, only $55(50 \%)$ of these were able to tell the action to be taken in case the progress of labor crossed the alert line. To improve on the knowledge on partograph use, $80 \%$ of the nurses wanted to receive refresher training on partograph use. This was elaborated during focus group discussion in Kiritiri when one member quoted.

We were taught these things in college but we never practiced and after working in other departments as a nurse you need refresher training on the use of these charts. Some of my colleagues trained as nurses before introduction of these chart.

When general knowledge was computed and a logistic regression done, it was found out that knowledge on partograph use was significant $(\mathrm{p} \leq 0.001)$. Majority of those who had good knowledge were 5.638 more likely to practice partograph use compared to those who had poor knowledge. When level of knowledge was adjusted for level of attitude, it was found out that $8.7 \%$ of the significance was attributed to the attitude of the respondent and remained significant $(\mathrm{p}=0.02$, CI 0.034 0.411 ) Table 7.

In FGD, among the reasons why nurses used a partograph were to monitor progress of labor, to detect complications and as a routine, we use a partograph to 


\section{Nursing \& Healthcare International Journal}

monitor the progress of labor,' (FGD nurse from Kianjokoma hospital). In addition, 'I use a partograph to detect any complications among mothers in labor' (FGD nurse from Kibugu hospital). A nurse from Kiritiri indicated 'we use a partograph as a routine in monitoring progress of labor' (FGD nurse from Kirirtiri hospital).

\begin{tabular}{|c|c|c|c|c|c|}
\hline \multirow{2}{*}{ Variable on Knowledge } & \multirow{2}{*}{ Category } & \multicolumn{2}{|c|}{ Use of partograph $(\mathrm{N}=110)$} & \multirow{2}{*}{$P$ df $\chi^{2}$} & \multirow{2}{*}{ Likelihood Ratio } \\
\hline & & Used & Not used & & \\
\hline \multirow{3}{*}{ Level of knowledge } & Good knowledge & $42(38.1 \%)$ & $24(21.8 \%)$ & \multirow{3}{*}{$\mathrm{P} \leq 0.05 \mathrm{df}=1 \chi^{2}=4.471$} & \multirow{3}{*}{$\mathrm{OR}=4.481$} \\
\hline & (Above 50\%) & & & & \\
\hline & $\frac{\text { Poor knowledge }}{\text { (Below } 50 \%)}$ & $19(17 \%)$ & $25(23 \%)$ & & \\
\hline
\end{tabular}

Table 7: General level of knowledge of nurses on correct use of a partograph.

Knowledge on components of a partograph: The nurses were also interviewed on knowledge on components of a partograph. From the study results it was evident that $44(40 \%)$ of the nurses were generally knowledgeable on components of the partograph. This implied that majority of the practicing nurses $66(60 \%)$ didn't understand all the components of the partograph.

Majority of the nurses 92 (83.6\%) knew that fetal heart rate was a component of a partograph, with 95 $(86.4 \%)$ eliciting cervical dilatation as a component of the partograph. Majority of the respondents 94 (85.5\%) reported that descent of the head was a component of the partograph and 100 (90.9\%) mention monitoring of maternal pulse as a component of the partograph. Most of the nurses reported that monitoring maternal temperature and checking if urine of the mother had ketones and proteins were components of a partograph $89(80.9 \%), 101$ (91.8\%) respectively.

Molding of the fetal skull and monitoring uterine contraction were also cited as components of partograph at $97(88.2 \%), 98(89.1 \%)$ respectively. Majority of the respondents $93(84.5 \%)$ also reported that monitoring of the color of amniotic fluid is a component of the partograph Figure 2.

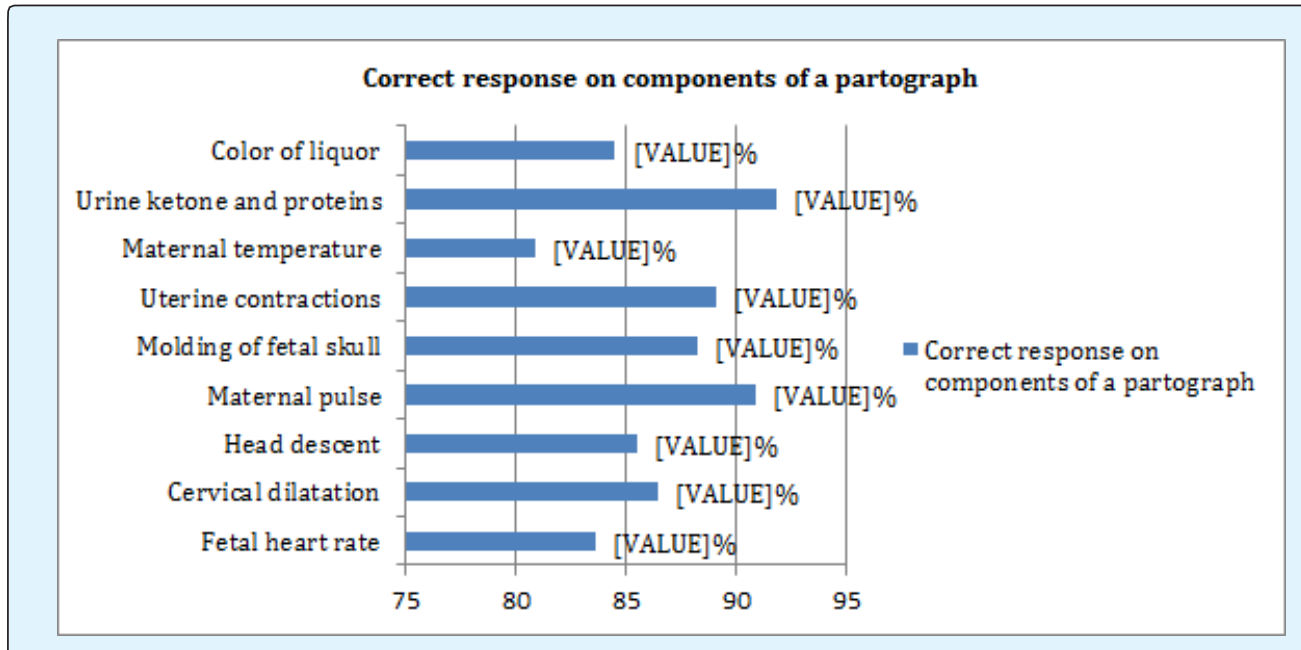

Figure 2: Components of a partograph.

When regression was conducted on knowledge on components of the partograph and use of the partograph, it was found to be significant ( $\mathrm{p} \leq 0.001)$. However, when the variable for knowledge was adjusted for attitude of the nurse, level of knowledge was insignificant $(p=0.097)$ Table 8. 


\section{Nursing \& Healthcare International Journal}

\begin{tabular}{|c|c|c|c|c|c|}
\hline \multirow[b]{2}{*}{$\begin{array}{c}\text { Variable on components of a } \\
\text { partograph }\end{array}$} & \multirow[b]{2}{*}{ Category } & \multicolumn{2}{|c|}{ Use of partograph $(\mathrm{N}=110)$} & \multirow[b]{2}{*}{ Pdf $\chi^{2}$} & \multirow[b]{2}{*}{$\begin{array}{l}\text { Likelihood } \\
\text { Ratio }\end{array}$} \\
\hline & & Properly used & $\begin{array}{l}\text { Not properly } \\
\text { used }\end{array}$ & & \\
\hline \multirow{2}{*}{$\begin{array}{c}\text { General knowledge on } \\
\text { components of a partograph }\end{array}$} & Good knowledge & $26(23.6 \%)$ & $18(16 \%)$ & $\mathrm{P} \leq 0.001 \mathrm{df}=1$ & \multirow{2}{*}{$\mathrm{OR}=5.638$} \\
\hline & Poor knowledge & $35(31.8 \%)$ & $31(28 \%)$ & $\chi^{2}=31.88$ & \\
\hline
\end{tabular}

Table 8: Knowledge on components of a partograph and partograph utilization.

Nurses attitude towards use of partograph: On assessing nurses' attitude towards use of partograph, a Likert scale was used. Four statements were used to assess the attitude of nurses. On the first statement, 19 $(17.3 \%)$ of the respondents strongly disagreed that a partograph can reduce newborn and maternal morbidity and mortality. About 13.6 per cent disagreed, 26.4 per cent agreed, $29.1 \%$ strongly agreed while 13.6 per cent were neutral.

On assessment if the partograph can be used in all labor, 16.4 per cent strongly agreed, 60.9 per cent agreed, 8.2 per cent disagreed, and one per cent of the respondents strongly disagreed while 13 per cent were neutral. 18.2 per cent of the respondents agreed that the partograph is an important tool in monitoring labor, 39.1 per cent disagreed to the statement, and 26.4 per cent strongly disagreed while 16.4 per cent were neutral.

Majority of the nurses 37 (33.6\%) reported that use of a partograph was time consuming and $17(15.5 \%)$ of the nurses also agreed that use of partograph took a lot of time they could have used to monitor the mother. 16
$(14.5 \%)$ of the respondents were neutral if the filling the partograph chart was time consuming with 19 (17.3\%) disagreeing that using the partograph was time consuming. In the same report $21(19.1 \%)$ of the nurses strongly disagreed that use of a partograph was time consuming.

Slightly less than half of the respondents strongly agreed and others agreed that they needed supervision for them to use a partograph 48 (43.6\%) and 41 (37.3\%) respectively. The nurses who were not sure if they needed supervision to fill a partograph when monitoring a mother in labor were $15(13.6 \%)$ and those who disagreed that they should be supervised to fill the partograph were 6 (5.5\%) Table 9.

Focused group discussion revealed that supervision among nurses could make nurses to utilize the partograph, nurses working in maternity need to be supervised and monitored frequently in order to be reminded to make utilization of partograph as a routine' (FGD nurse from Kianjokoma hospital).

\begin{tabular}{|c|c|c|}
\hline Attitude Variable & Response & Frequency \\
\hline \multirow{4}{*}{ Partograph is important in monitoring labor } & Agree & $20(18.2 \%)$ \\
\hline & Neutral & $18(16.4 \%)$ \\
\hline & Disagree & $43(39.1 \%)$ \\
\hline & Strongly disagree & $29(26.4 \%)$ \\
\hline \multirow{5}{*}{ Partograph should be used in all labor } & Strongly agree & $18(16.4 \%)$ \\
\hline & Agree & $67(60.9 \%)$ \\
\hline & Neutral & $15(13.65)$ \\
\hline & Disagree & $9(8.2 \%)$ \\
\hline & Strongly disagree & $1(0.9 \%)$ \\
\hline \multirow{5}{*}{$\begin{array}{l}\text { Partograph can reduce newborn and maternal morbidity and } \\
\text { mortality }\end{array}$} & Strongly agree & $32(29.1 \%)$ \\
\hline & Agree & $29(26.4 \%)$ \\
\hline & Neutral & $15(13.6 \%)$ \\
\hline & Disagree & $15(13.6 \%)$ \\
\hline & Strongly disagree & $19(17.3 \%)$ \\
\hline \multirow{5}{*}{ Using partograph is time consuming } & Strongly agree & $37(33.6 \%)$ \\
\hline & Agree & $17(15.5 \%)$ \\
\hline & Neutral & $16(14.5 \%)$ \\
\hline & Disagree & $19(17.3 \%)$ \\
\hline & Strongly disagree & $21(19.1 \%)$ \\
\hline
\end{tabular}

Boraya JO, et al. Utilization of Partograph in the Management of Women in Labor among Nurses Working in Embu County, Kenya. Nurs Health Care Int J 2019, 3(2): 000181. 


\begin{tabular}{|l|c|c|}
\hline \multirow{4}{*}{ Need supervision to use partograph } & Strongly agree & $48(43.6 \%)$ \\
\cline { 2 - 3 } & Agree & $41(37.3 \%)$ \\
\cline { 2 - 3 } & Neutral & $15(13.6 \%)$ \\
\cline { 2 - 3 } & Disagree & $2(2.1 \%)$ \\
\cline { 2 - 3 } & Strongly disagree & $4(3.4 \%)$ \\
\hline
\end{tabular}

Table 9: Nurses attitude towards utilization of a partograph.

Another respondent said, majority of the nurses do not bother to complete most parameters of the partograph after the mother delivers" (FGD nurse from Kianjoka level 4 hospital). Another nurse revealed that, "nurses do not complete the partograph because some of the information is transferred to other documents such as the cardex which makes nurses not to replicate the same information" (FGD nurse from Machakos level 5 hospital).

On further probing why the partographs were not complete, members reported that; Majority of the nurses do not bother to complete most parameters of the partograph after the mother delivers" (FGD nurse from Kiritiri hospital).
Another nurses revealed that, "nurses do not complete the partograph because some of the information is transferred to other documents such as the cardex which makes nurses not to replicate the same information" (FGD nurse from Kianjokoma hospital).

General assessment of attitude among nurses towards partograph use: Assessment on the general attitude of the nurses on partograph use, more than a half of the respondents 74 had a negative attitude. Only 24 of these respondents who had a negative attitude had filled the partograph. However, out of 36 respondents who had a positive attitude, 30 of them had filled the partograph. On computation of these results, attitude of the nurse was significantly affecting use of the partograph $(\mathrm{p}=0.001$, $\chi^{2}=25.1$ ) Table 10 .

\begin{tabular}{|c|c|c|c|c|c|}
\hline \multirow{2}{*}{ Variable } & \multirow{2}{*}{ Category } & \multicolumn{2}{|c|}{ Use of partograph } & \multirow{2}{*}{ P value } \\
\cline { 3 - 4 } & & Properly used & Not properly used & \multirow{2}{*}{ df } & \\
\hline \multirow{2}{*}{ General attitude of nurses } & Positive attitude & $24(21.8 \%)$ & $50(45.4 \%)$ & \multirow{2}{*}{2} & $\mathrm{p} \leq 0.001 \chi^{2}=25.1$ \\
\cline { 2 - 4 } & Negative attitude & $30(27 \%)$ & $6(4 \%)$ & &
\end{tabular}

Table 10: Nurses attitude on use of partograph.

During the discussion nurses revealed that utilization of the partograph was time consuming, there was lack of training on partograph use and lack of partograph papers was reported, partograph consumes a lot of time in documentation while monitoring women in labor (FGD nurse from Kianjokoma hospital).

Others revealed that lack of training contributed to lack of utilization of the partograph, we never receive trainings on partograph use therefore we don't have the latest updates on partograph utilization (FGD nurse from Kibugu hospital).

Key informant from Kibugu and Kianjokoma hospitals reported that nurses related factors influencing utilization of a partograph to be negative attitude among nurses working in labor ward and lack of adequate supervision from the ward in charges, Some nurses working in maternity ward have negative attitude towards utilization of partograph because they feel that there is a lot of documentation in the unit' (key informant from
Kianjokoma hospital). In addition, 'there was lack of supervision from the unit in charge because some nurses needed supervision in order to utilize the partograph' (key informant from Kibugu hospital).

The key informers revealed that negative attitude among nurses working in labor ward and lack of resources to influence utilization of the partograph, some nurses feel that utilization of the partograph is tedious and instead prefer documenting the findings on the cardex" (key informer from Kianjokoma hospital).

Sometimes there were no enough papers used to monitor progress of labor, labor wards lacked partograph papers which led to inadequate documentation of the findings during labor" (key informant from Kiritiri hospital).

Nurses training on partograph use: The nurses who had been trained on partograph use after college were less than half $47(42.6 \%)$ of the respondents, the 
frequency of workshops varied significantly from one respondent to another; those who had never attended to any training were 69 (62.7\%), those who attended training in every three months were $24(21.8 \%)$ while those who received training once a year were 17 (15.5\%). When those nurses who had been trained were interviewed on improved use of partograph after training, more than half of the nurses $86(78.2 \%)$ reported improvement on use of partograph while $24(21.8 \%)$ had no improvement. The nurses who had undergone on job training were 5.5 times more likely to have more knowledge on use of a partograph than those who had not been trained Figure $3 \&$ Table 11.

FGD revealed inadequate training among the majority of nurses, i have worked in maternity for more than 2 years but I have never been trained on partograph use' (FGD nurse from Kibugu hospital). Similar sentiments were shared by a midwife "I am trained as a midwife but I have never received any training on partograph since devolution started" (FGD nurse from Kianjokoma hospital).

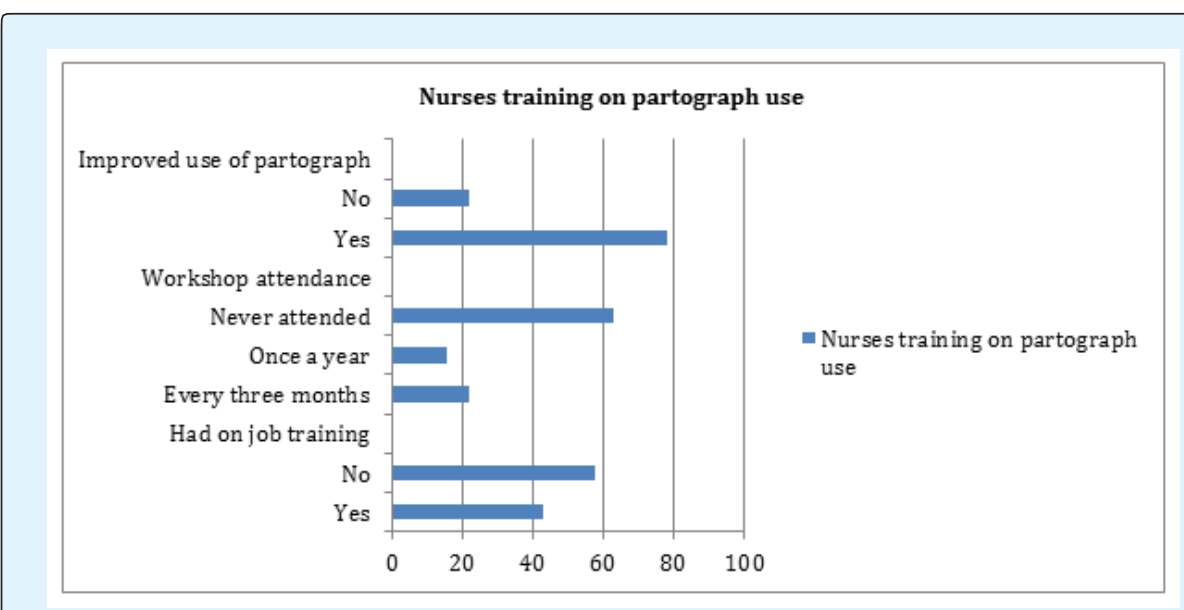

Figure 3: Nurses training on partograph use.

On computation of the results after analysis on the effect of training on partograph use, the findings were statistically significant, as shown in the table below.

\begin{tabular}{|c|c|c|c|c|}
\hline Partograph training variable & Response & \multicolumn{2}{|c|}{ Use of partograph (N=110) } & P Value \\
\hline \multirow{2}{*}{$\begin{array}{c}\text { Attended on job training on } \\
\text { partograph use }\end{array}$} & Yes & $27(24.5 \%)$ & $20(18.1 \%)$ & \multirow{2}{*}{$\mathrm{P}=0.001 \chi^{2}=12.12$} \\
\cline { 2 - 4 } & No & $45(40.9 \%)$ & $18(16.3 \%)$ & \multirow{2}{*}{$\mathrm{P}=0.001 \chi^{2}=26.029$} \\
\hline \multirow{2}{*}{$\begin{array}{c}\text { Frequency of trainings on } \\
\text { partograph use }\end{array}$} & Every 3 months & $15(14 \%)$ & $9(8 \%)$ & $29(26 \%)$ \\
\cline { 2 - 4 } & Yearly & $40(36 \%)$ & $11(10 \%)$ & \\
\cline { 2 - 4 } $\begin{array}{c}\text { Improved partograph use after } \\
\text { training }\end{array}$ & Yes & $6(5 \%)$ & $15(14 \%)$ & \multirow{2}{*}{$\mathrm{P}=0.178 \chi^{2}=3.456$} \\
\cline { 2 - 4 } & No & $9(8 \%)$ & $21(19 \%)$ & \\
\hline
\end{tabular}

Table 11: Effect of training of nurses on partograph utilization.

\section{Discussion}

General knowledge of nurses on partograph use indicated that $59.9 \%$ had good knowledge (above 50\%) on partograph use. When general knowledge was computed, it was found out that knowledge on partographing was significant $(\mathrm{p}=0.001)$. This resonates well with the findings by Yisma, et al. [8] where more than half (53.1\%) of the respondents had good knowledge on partograph use. In addition, from the study findings, majority of those who had good knowledge were five times more likely to practice partographing compared to those who had poor knowledge on partograph use.

Knowledge on components of partograph was significant towards utilization of the partograph. From the study results it was evident that $60 \%$ of the nurses were generally knowledgeable on components of the 


\section{Nursing \& Healthcare International Journal}

partograph while $40 \%$ didn't understand all the components of the partograph. This is shared by Fawole, et al. [9] where $54 \%$ of nurses working in labor wards interviewed knew the components of the partograph. However, knowledge among the respondents on the components of the partograph did not translate to proper utilization of the partograph as the study findings showed that less than half $44.6 \%$ did not utilize the partograph despite having adequate knowledge on the components of the partograph.

Training after college was another variable on nurses related factors influencing utilization of the partograph. The findings showed that $42.6 \%$ of the respondents had been trained on partograph use after college. This is in line with literature confirming this relationship [4] where being trained on partograph use the management of pregnant mothers in labour was a strong predictor in the logistic model reporting the proper use of the partogram. From the focused group discussions, some nurses reported that they had worked in maternity for more than 2 years yet they have never been trained on partograph use.

When those nurses who had been trained were interviewed on improved use of partograph after training, majority $78.2 \%$ of the nurses reported improvement on use of partographs. Through safe motherhood initiative, one-time training did not show a significant impact on utilization of the partograph rather a serial of the trainings which updates midwives on partograph use. SMH is important in providing ongoing education, quality assurance and supervision in order to have a lasting impact on partograph completion. From the study area, nurses reported through focused discussions that they were trained as midwives but they have never received any training on partograph since devolution started which influenced partograph use.

Although all nurses working in labor ward interviewed in this study had formal training on how to use the partogram, the impact of such training was not reflected in their performance. Results from the present study revealed a statistical significant association between the utilization of partogram and whether the nurses had received in-service training. These findings are confirmed by the results from Yisma, et al. [8], where more nurses who had not been previously trained on the partograph had lesser odds of utilizing the partograph compared to those who had been previously trained.

General assessment of attitude among nurses was significant towards partograph use. Majority (67.2\%) of the respondents had negative attitude towards partograph use. The same sentiments were reported during a focused group discussion in Kianjokoma where they indicated that some nurses working in maternity ward have negative attitude towards utilization of partograph because they felt that the partograph required a lot of documentation. The attitude of a midwife has a potential influence on partograph utilization, without positive attitude the partograph cannot guide health care provider to take appropriate decisions during labor. These were also echoed by Zelellw, et al. [10] in a study which revealed that good knowledge and favorable attitude improves partograph use.

\section{Conclusion}

Nurses related factors influencing utilization of the partograph include negative attitude and lack of training on partograph use. Majority of nurses working in labor ward felt that partograph use is time consuming and needed supervision on partograph use. In addition, majority of the nurses were not trained on partograph use from the time they graduated from college.

\section{Recommendation}

The study recommends policy makers and nursing administrators to ensure that all qualified nurses use the partograph in the care of women in labour.

\section{References}

1. Lavender T, Hart A, Smyth RM (2013) Effect of partogram use on outcomes for women in spontaneous labour at term. Cochrane Database Syst Rev (7): CD005461.

2. Soni BL (2014) Effect of partogram use on outcomes for women in spontaneous labour at term: RHL commentary. The WHO Reproductive Health Library, World Health Organization, Geneva.

3. Magon N (2013) Partograph Revisited. International Journal of Clinical Cases Investigations 3: 1-6.

4. Mandiwa C, Zamawe C (2017) Documentation of the partograph in assessing the progress of labour by health care providers in Malawi's South-West zone. Reprod Health 14(1): 134.

5. WHO (2014) Trends in maternal mortality: 19902013. Estimates by WHO, UNICEF, UNFPA, the World Bank and the United Nations population, World Health Organization, Geneva, Switzerland. 
6. Kenya Demographic and Health Survey (KDHS) (2014-2015) Count down to 2015 Maternal and Child Survival, Kenya.

7. Rotich E, Maina L, Njihia A, Christensson K (2011) Evaluating partograph use at two main referral hospitals in Kenya. African Journal of Midwifery and Women's Health 5(1): 21-24.

8. Yisma E, Dessalegn B, Astatkie A, Fesseha N (2013) Knowledge and utilization of partograph among obstetric care givers in public health institutions of Addis Ababa, Ethiopia. BMC Pregnancy Childbirth 13: 17.
9. Fawole AO, Hunyinbo KI, Adekanle DA (2013) Knowledge and utilization of the partograph among obstetric care givers in South West Nigeria. Afr J Reprod Health 12(1): 22-29.

10. Zelellw D, Tegegne T, Getie G (2016) Knowledge and attitude of obstetric care providers on partograph and its associated factors in East Gojjam Zone, North West Ethiopia. Advances in medicine 2016: 8. 